\title{
Asthma in the Army: A Retrospective Study and Review of the Natural History - of Asthma and its Implications for Recruitment
}

\section{Lt Col J G Dickinson}

DM, FRCP, DTM\&H, RAMC

Consultant Physician

Queen Elizabeth Military Hospital, Woolwich

SUMMARY: In an attempt to define the problem of asthma in the British Army and to relate it to recruiting policy, records were obtained for all discharges from the Army and all admissions to hospital for 48 hours or more with a principle diagnosis of asthma over four years. There were approximately 50 medical discharges from asthma per year, $\propto$ representing about 1 in 3400 of the held strength of the Army and $6.3 \%$ of the discharges from all medical causes. The $\tilde{D}$ average number of non-effective days before discharge was about 20 and those discharged were generally young $(57 \% \vec{\circ}$ aged 20 years or less), of short service (47\% less than 2 years service) and of low rank (86\% privates, apprentices or juniors). Three hundred and fifty two individuals were admitted to hospital on 415 occasions in 4 years, of whom 82 were $\vec{\omega}$

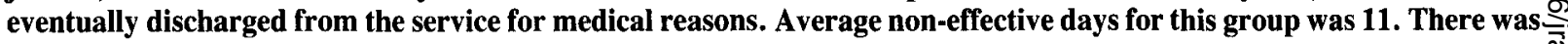
only one death.

Of 108 discharged soldiers who were eventually shown to have a history of asthma in childhood (HAC), this was identified at recruit examination in only $43 \%$. Before enlistment, only $20 \%$ were referred for consultant opinion and only $\vec{\omega}$ $6 \%$ had exercise testing. $28 \%$ were probably current asthmatics on entry.

From available records, age of remission of childhood asthma was most commonly 10-14 years (64\%). Relapse was $N$ commonest at age 17-21 years $(76 \%)$ with $25 \%$ of relapses occurring at 18 years. Development of asthma for the first time $\dot{\omega}$ during service occurred most commonly at 17-20 years (62\%). Exercise testing was done in 113 of those discharged and $\circ$ was normal in $20 \%$ of these.

Review of the available literature on the natural history of childhood asthma in the context of current recruiting polię $\vec{c}$ justifies a rough prediction that, of those accepted in remission in mid teens, $40 \%$ will be wheeze free in their late twentie $\mathbf{2 5} \%$ will have suffered some wheeze that may have led to downgrading and even discharge and $35 \%$ will have been discharged because of asthma. It is recommended that candidates with a history of asthma should not be accepted before $\vec{\emptyset}$ the age of 22 years.

\section{Introduction}

Asthma is a difficult subject. Like love ${ }^{1}$ we think we know what it is, but precise definition eludes us. Attempts such as "short term variability in expiratory airflow resistance" have not been accepted internationally ${ }^{2}$ because of the difficulty in quantifying them, ("How much variability?") and because some of the more severe asthmatics show very little variation. Similarly, it is very difficult to stratify asthma into grades of severity ${ }^{3}$ because of its irregular and intermittent nature; an asthmatic can be playing vigorous sport one day and the next finding difficulty walking on the flat.

From the military point of view, it is clear that service life is unsuitable for most asthmatics. Exercise, cold, stress, dust and cigarette smoke are common precipitants that are unavoidable. Unpredictable physical performance in a soldier is not conducive to the smooth functioning of a unit. Selection presents its own problems; military recruitment concentrates on the 1618 year age group, the age at which many childhood asthmatics are in remission, but poised to relapse. Tests for airways obstruction are rarely positive during prolonged remissions, or indeed between attacks, so that assessment of the severity of an asthma history is based on the subjective impressions of a candidate who will see advantages in minimising it.
It is now generally recognised in the medicit profession that 'wheezy bronchitis' in children is indis? tinguishable from asthma ${ }^{4}$, but teenagers may deny in good faith a history of asthma while admitting to 'bronchitis', 'wheeze' and 'chestiness' or even give the name 'hay fever' to typical asthma attacks. Some may deliberately conceal a history of asthma in order to be enlisted and a knowledgeable asthmatic could foil physical examination and even exercise testing by clandestine use of inhalers or systemic steroids.

Current regulations, introduced in April 1986; (JSP 346,0420 ) call for rejection of candidates with asthma or wheezy bouts requiring treatment in the previous four years. Candidates with a history of earlier wheezing are to be assessed by a Service consultant and a positive exercise or bronchial lability test is sufficient reason for rejection, though testing is not mandatory. Almost all the subjects in this study were recruited under previous $₹$ regulations, namely “. . . consultant opinion should 을 usually be sought. Candidates judged to be asthmatic (liable to recurrent attacks) and those currently on long term therapy are to be assessed P8" (that is, unfit for service).

This study was undertaken to obtain epidemiological $N$ information on the size and pattern of the problem of $N$ asthma in the Army and to match it as far as possible 
with current knowledge of the natural history of the condition.

\section{Method}

Data were obtained from the tri-service Medical Statistics branch of the Ministry of Defence at Stanmore. The TRIMEDS system was used to obtain listings, sorted in various ways, of medical discharges and bedded sickness events of 48 hours or more with a principle diagnosis of asthma (ICD code 493). For the discharges only, copies of the microfilmed entry Medical Examination Record ( $F$ Med 2) and the discharge Medical Board Record (F Med 23) were obtained through the CARMED computer-assisted retrieval system. Neither of these documents was available for 2 of the 201 persons discharged and F Med 2 was not available in $59(29 \%)$. However there were sufficient documents for adequate analysis. This information was used to build up a partial epidemiological picture of asthma in the Army.

\section{Results}

\section{Adequacy of documents}

Of 199 sets of documents available, it was not possible even in retrospect to determine whether or not there was a past history of asthma in $31(16 \%)$. From 47 of the records $(24 \%)$ the age at which asthma began or recurred during service life could not be determined. Fourteen records gave this age without indicating whether it represented recurrence or onset for the first time. Of 60 patients with apparent adult onset, the age of onset could not be determined in two, and in 108 of those who had $\mathrm{HAC}$, the age of remission was not stated in $28(26 \%)$.

\section{Asthma as a cause for medical discharge}

Table 1 summarises the discharges over 4 years, which were reasonably constant and averaged 50 per year. Asthma caused $8 \%$ of discharges from all diseases and $6.3 \%$ of all medical causes. There was an average of 29 discharges per 100,000 total Army strength (including Gurkhas) per year, or 1 serviceman in 3400 per year.

\section{Asthma as a cause of loss of manpower}

Those discharged averaged 20 days non-effective before discharge. For those admitted to hospital (including some, but not all, of the discharged persons) the average total non-effective time was 11 days. Recorded manpower loss totalled 3919 days in 4 years. There was one death due to asthma in the period.

\section{Sex and age}

Only one of 201 persons discharged because of asthma was female and only $5 \%$ of the admissions to hospital involved servicewomen. (About $4 \%$ of serving personnel are female). Table 2 shows the age distribution of those discharged and the age-specific rates. Figure 1 shows this graphically and emphasises that $57 \%$ were aged 20 years or less and only $9.5 \%$ were 26 years or older. Figure 2 shows a slightly different pattern for hospital admissions; only $35 \%$ were 20 years or less and $35 \%$ were 26 years or over. This probably reflects a tendency to retain the more experienced serviceman albeit in a lower medical category.

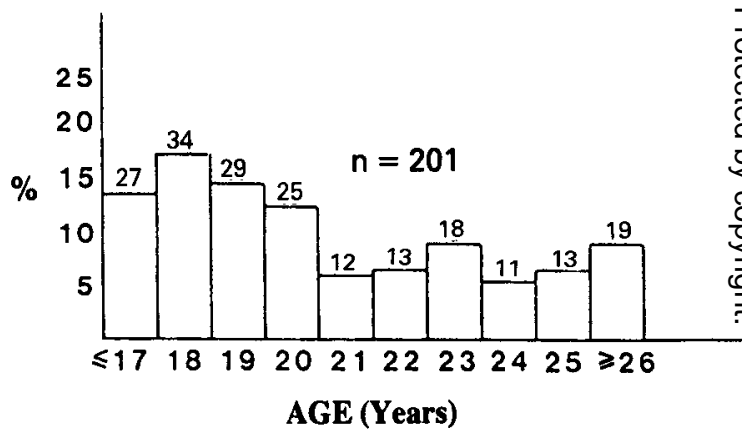

Fig 1 Age Distribution of Discharges due to Asthma 1983-6

Note. In all figures, numbers above the bars represent numbers in each group.

Table 1

Asthma as a Cause of Medical Discharge from the Army

\begin{tabular}{cccccc}
\hline Year & $\begin{array}{c}\text { Discharges } \\
\text { (asthma) }\end{array}$ & $\begin{array}{c}\text { Discharges } \\
\text { (diseases) }\end{array}$ & $\begin{array}{c}\text { Discharges } \\
\text { (all causes) }\end{array}$ & $\begin{array}{c}\text { Asthma \% } \\
\text { of diseases }\end{array}$ & $\begin{array}{c}\text { Asthma \% } \\
\text { of all causes }\end{array}$ \\
\hline $\mathbf{1 9 8 3}$ & 35 & 409 & 513 & 8.6 & 6.8 \\
$\mathbf{1 9 8 4}$ & 56 & 571 & 710 & 9.8 & 7.9 \\
$\mathbf{1 9 8 5}$ & 57 & 774 & 1015 & 7.4 & 5.6 \\
$\mathbf{1 9 8 6}$ & 53 & 744 & 947 & 7.1 & 5.6 \\
\hline TOTAL & 201 & 2498 & 3185 & 8.0 & 6.3 \\
\hline
\end{tabular}


Table 2

Discharges by Age 1983-86

\begin{tabular}{|c|c|c|c|c|}
\hline $\begin{array}{c}\text { Age } \\
\text { (years) }\end{array}$ & $\begin{array}{l}\text { Discharges } \\
\text { (No.) }\end{array}$ & $\begin{array}{c}\text { Discharges } \\
\%\end{array}$ & $\begin{array}{c}\text { Strength } \\
\text { (thousands) }\end{array}$ & $\begin{array}{c}\text { Rate per } \\
100,000 \text { strength }\end{array}$ \\
\hline$\leqslant 17$ & 27 & 13.4 & 37.8 & 7.14 \\
\hline 18 & 34 & 16.9 & 34.8 & 9.77 \\
\hline 19 & 29 & 14.4 & 41.7 & 6.95 \\
\hline 20 & 25 & 12.4 & 46.0 & 5.43 \\
\hline 21 & 12 & 6.0 & 43.7 & 2.75 \\
\hline 22 & 13 & 6.5 & 42.0 & 3.10 \\
\hline 23 & 18 & 9.0 & 41.0 & 4.40 \\
\hline 24 & 11 & 5.5 & 37.7 & 2.92 \\
\hline 25 & 13 & 6.5 & 34.5 & 3.77 \\
\hline \multirow[t]{2}{*}{$\geqslant 26$} & 19 & 9.5 & 285.2 & 6.66 \\
\hline & 201 & 100 & 644.4 & 31.19 \\
\hline
\end{tabular}

Notes: 1. Strengths rounded to the nearest thousand

2. Figures obtained from Stats (Manpower) and exclude Gurkhas (among whom there were no discharge@ due to asthma).

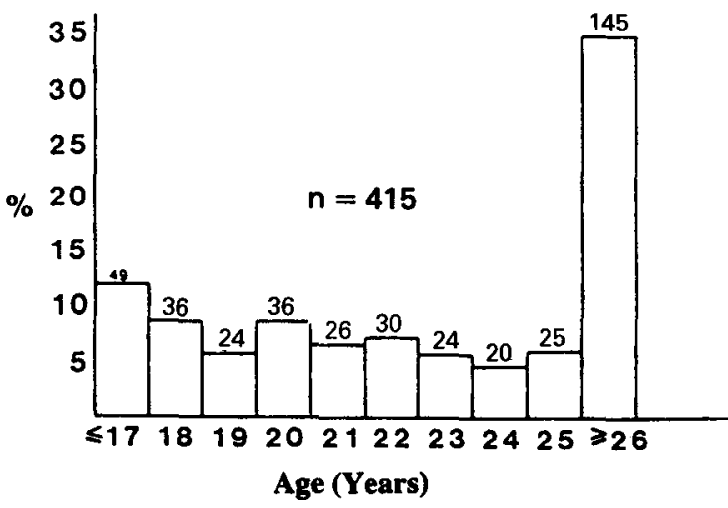

Fig 2 Age Distribution of In Patient Events Due to Asthma 1983-6

\section{Length of service and rank}

Figure 3 shows that $60 \%$ of servicemen were discharged before reaching 3 years of service, $47 \%$ within 2 years, and $16 \%$ were discharged within the first 6 months. Many of these were probably current asthmatics on entry. Commensurate with the short service, discharged personnel were mostly of low rank, $86 \%$ being privates, apprentices or junior soldiers. Table 3 illustrates this and gives rates per 100,000 Army strength in the individual ranks.

\section{Outcome of admissions to hospital}

There were 415 admissions to hospital of $48 \mathrm{hrs}$ or more, involving 352 patients of whom 38 were admitted on two occasions, 6 on three occasions and one each on

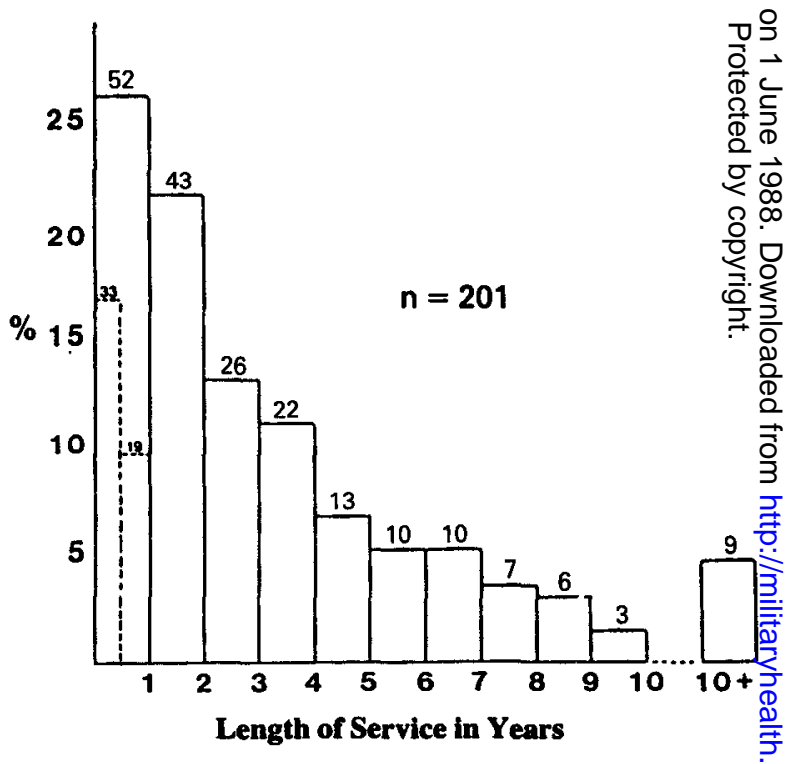

Fig 3 Length of Service Before Medical Discharge Due to Asthma

4, 5 and 7 occasions. There was one death and 39 were음 recommended for medical discharge immediately after $>$ admission. Including these, 82 were eventually을. medically discharged from the Army, 77 of them with añ principle diagnosis of asthma. This leaves at least $269^{\circ}$ $(76 \%)$ who were admitted to hospital for treatment of asthma but were not obliged to leave the service because $\widetilde{N}$ of it. 
Table 3

Discharges by Rank 1983-86

\begin{tabular}{lrccc}
\hline Rank & No. & $\%$ & Strength & $\begin{array}{c}\text { Rate Per } \\
\text { 100,000 Strength }\end{array}$ \\
\hline Junior & 15 & $7.5)$ & & 116.3 \\
Apprentice & 19 & ) & 29227 & 58.9 \\
Private & 138 & $9.5)$ & & 19.6 \\
LCpl & 19 & 68.7 & 234140 & 4.0 \\
Cpl & 4 & 9.5 & 96964 & - \\
Sgt & 0 & 2.0 & 99358 & 3.2 \\
SSgt & 1 & 0.5 & 31167 & - \\
WO2 & 0 & - & 23708 & - \\
WO1 & 0 & - & 8779 & 7.6 \\
All Officers & 5 & 2.5 & 65933 & 30.9 \\
\hline
\end{tabular}

Notes: Strengths obtained as for Table 2, but not rounded.

\section{Relation to history of asthma in childhood}

Of 199 documented medical discharges, study of available records revealed a definite HAC in $108(54 \%)$. Sixty $(30 \%)$ were recorded as having no HAC and in 31 $(16 \%)$ there was no mention of HAC, whether positive or negative. Of the 37 who, on review of all documents appeared to be current asthmatics on entry, 30 had HAC recorded, one was said to have had no childhood asthma and there was no record in the remaining six.

\section{Ages of remission, relapse and onset}

Of the 108 patients with definite HAC the age of remission was recorded in 50 and the distribution of these is given in Figure 4. Sixty-four percent of remissions occurred between the ages of 10 and 14 years The distribution of the age of relapse of those with HAC is given in Figure 5 and shows that $76 \%$ of relapse occurred between the ages of 17 and 21 years. The average age of relapse was 19.3 years and $25 \%$ o

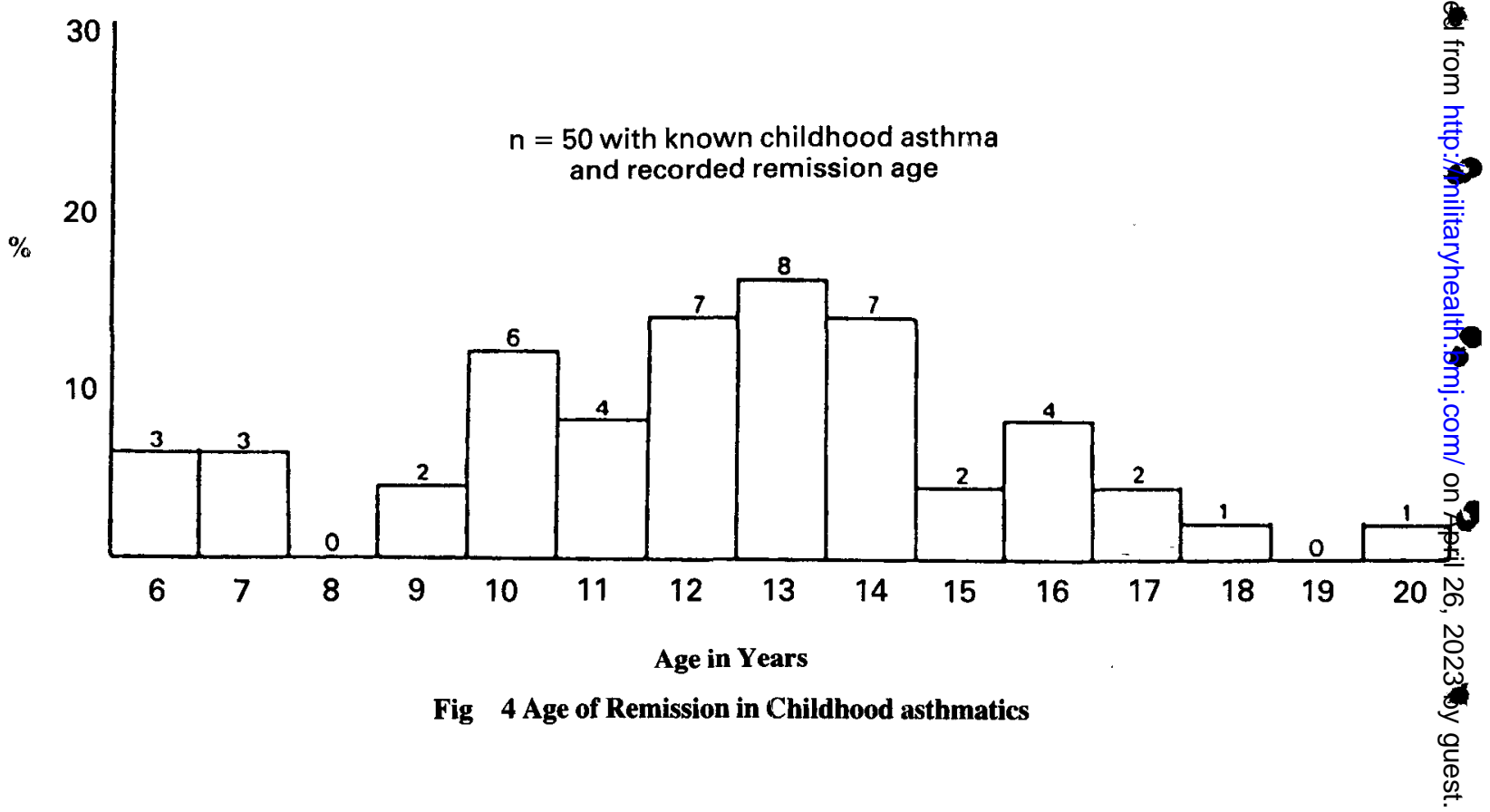




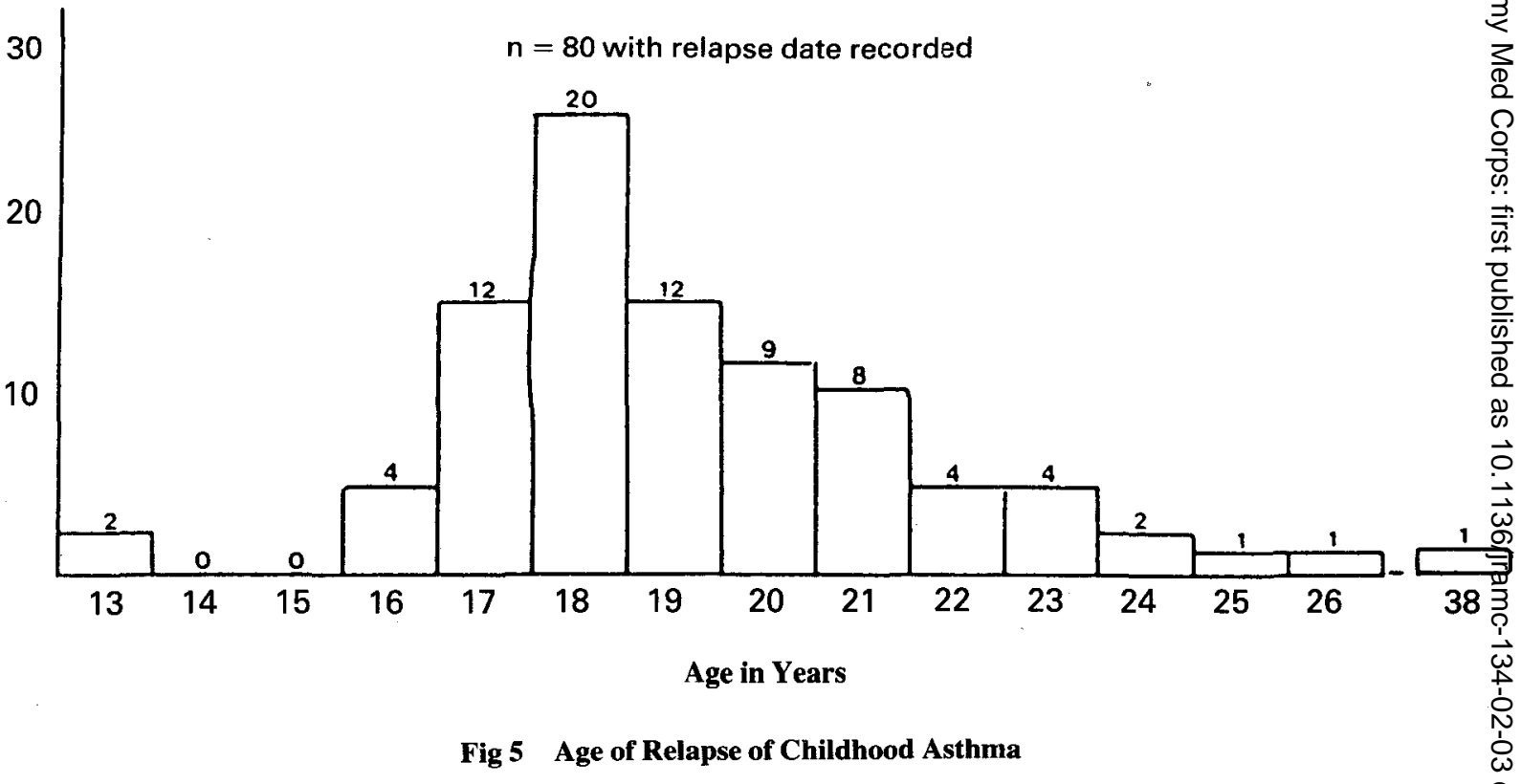

Fig 5 Age of Relapse of Childhood Asthma

relapses occurred at age 18 years. Figure 6 shows the ages of onset of asthma in 58 patients of the 60 who were recorded as not having had HAC. Sixty five percent of these began to have asthma between the ages of 17 and 21.

\section{Detection of childhood asthma at recruit medical examination}

Of 108 persons shown in retrospect to have been childhood asthmatics, only $43 \%$ were detected at recruit examination. Some of the remainder may not have known that they had asthma, or their families and doctors may have used other terms. In several cases subsequent records showed that HAC had been deliberately concealed. Only $20 \%$ had consultant opinions entered on F Med 2 and only $6 \%$ had exercise testing, which was negative in all cases. Under the current regulations, possibly more would have been referred.

\section{Current asthma on entry}

Of 37 persons judged in retrospect to have been asthmatic on enlistment, there was a definite HAC in 30 . Thus 37 of the total documented group of 199 were currently asthmatic on enlistment $(19 \%)$ and of the "former" asthmatic group 30 of $108(28 \%)$ were still actively asthmatic.

\section{Exercise testing}

Spirometry before and after exercise is not necessary for the diagnosis of most cases of asthma. Nonetheless 113 of the discharged soldiers underwent exercise testing, mostly shortly before discharge. Results are given in Table 4. Using an upper limit of normal labiläyof $15 \%{ }^{5}$ normal results were found in $20 \%$ of the tested.

Examination of potential recruits and potential officers

In the four months, April to July 1987, 62 candidafs with HAC were reviewed at QEMH of whom 53 wexeo male. Nine of the 62 were rejected $(14.5 \%)$. A simi in number is seen at the Cambridge Military Hospital, $\overrightarrow{\mathrm{s}} 0 \overline{\mathrm{O}}$ that a rough annual estimate for Wales and the southerno part of England is 370 reviewed and 320 accepted. We@ do not know how many eventually enter service, though $\overrightarrow{\overrightarrow{0}}$ Lynch-Blosse ${ }^{6}$ states that only $33 \%$ of serious applicants are enlisted and only 1 in 4 complete basic training. Reasons for withdrawal are largely non-medical.

\section{Discussion}

The cost of asthma to the Army can roughly be expressed as 50 medical discharges, 100 hospitab admissions and 1000 non-effective days per year. Using the present methods, it is not possible to measure the cost in terms of downgrading, disability and non- $\frac{\sigma}{3}$ effectiveness in those who are not admitted to hospitas. or discharged from the service, but experience in? medical outpatients suggests that it may be considerable. In addition, the milder asthmatics may bes managed entirely in unit medical centres. The findings of this paper are reflected in a study of medical wastage of recruits by Lynch-Blosse ${ }^{6}$ in which 11 recruits weres discharged because of asthma in a year out of a total of 208 medical discharges. For comparison, knee pain ledo to 73 of the discharges and asthma constituted 11 out of 47 discharges under $\mathrm{P}$ quality $(23 \%)$. Four out of the $11 \%$ 


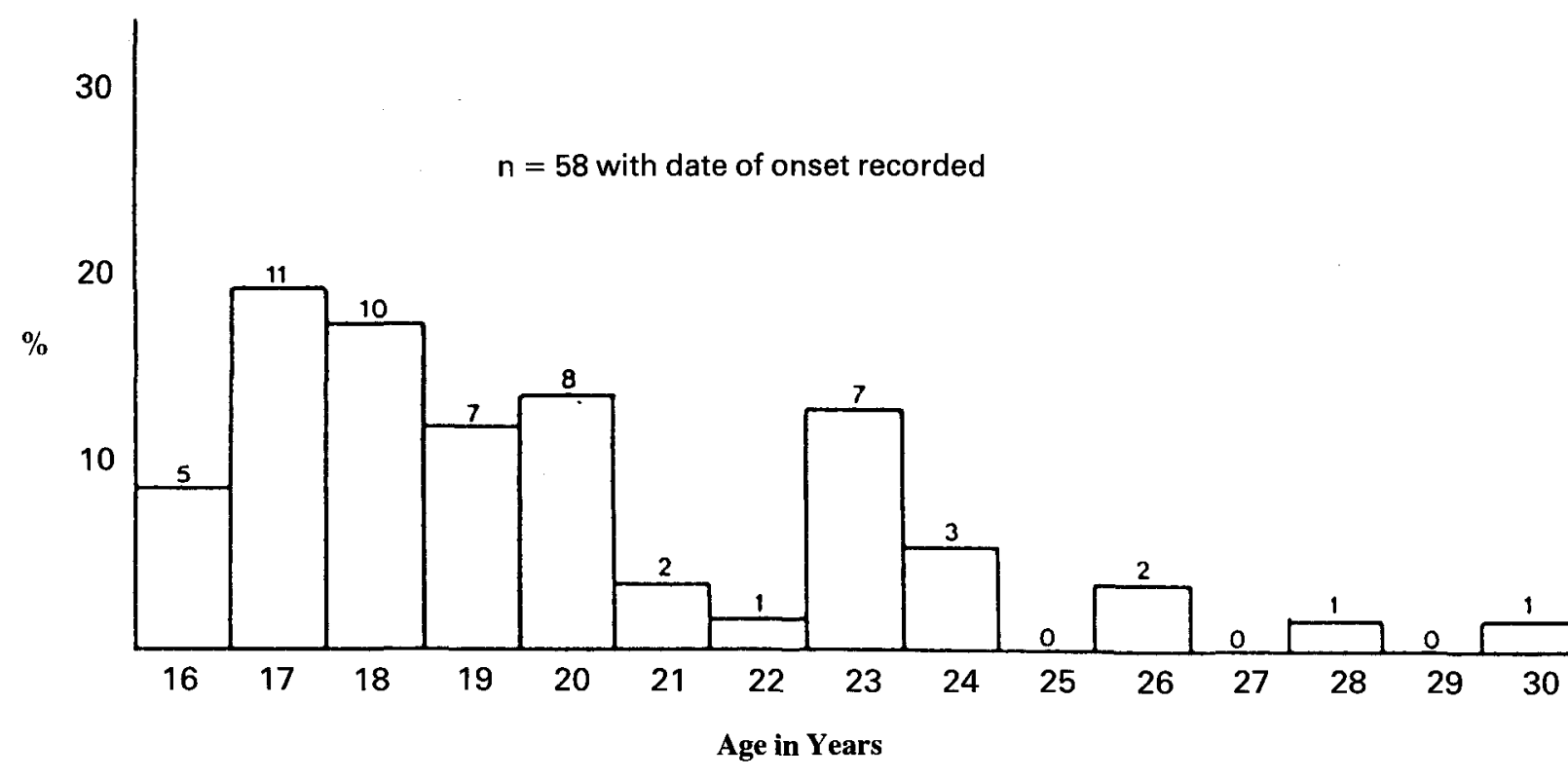

Fig 6 Age of Onset in those without a History of Childhood Asthma

Table 4

Results of Exercise Vitalograph in 113 Discharged Personnel Tested

\begin{tabular}{lrrr}
\hline *Fall or lability index & No. & $\%$ & \\
\hline Normal, unspecified & 6 & $5.3)$ & $0.7)$ \\
$0-9.9 \%$ & 11 & $4.4)$ & $19.5 \%$ \\
$10-14.9 \%$ & 5 & & \\
& & $13.3)$ \\
$15-19.9 \%$ & 15 & $5.3)$ & $80.5 \%$ \\
$20-24.9 \%$ & 6 & $57.5)$ & \\
More than 25\% & 65 & $4.4)$ \\
Abnormal, unspecified & 5 & 100 & \\
\hline
\end{tabular}

*Fall index was used when lability index was not recorded and in three instances in which fall exceeded lability, probably due to an error in calculation or recording.

were considered to be instances of concealment by the recruit before entry and in the remaining 7 asthma was noted at pre-entry medical but thought to be 'worth a try'.

Asthma thus seems to be a significant cause of medical wastage among recruits and relatively young soldiers, and it becomes important to enquire if this could be reduced by stricter selection procedures. Some $30 \%$ of those discharged had no definite HAC and only one of these was currently asthmatic on entry. As shown by
Winfield and Carson ${ }^{7}$ exercise testing is unlikely to pick up asthmatics in remission. It may help exclude current asthmatics unless they confound the test by using medication. Increased bronchial reactivity to methacholine or histamine provocation may be present in asthmatics, but there is too much overlap with normals to be of much value in selection ${ }^{8}$. It is also time consuming and carrries a risk of causing a severe asthmatic attack ${ }^{8}$. Undoubtedly careful and sympathetic history taking would reduce the number of current 
asthmatics accepted and draw attention to a larger number of childhood asthmatics.

Applying the conclusions of Bonner ${ }^{9}$, we might define the ideal recruit from the point of view of a low risk of developing asthma. He, or rather she, would be a white, breast-fed female who comes from a non-atopic, nonsmoking family, who has never experienced wheeze, asthma, eczema or hay fever and who does not smoke. It being impracticable to apply all these criteria, it seems reasonable to concentrate on past and present asthma and possibly other atopic features. Infantile eczema in particular seems to be associated with severe asthma, but there is no clear relationship to prognosis. ${ }^{10}$

The main issue, therefore, is whether candidates known to be in remission following childhood asthma should be accepted or rejected. Those in favour of rejection point to the expense incurred in training recruits who are forced to drop out at an early stage of their service career, the expense and manpower involved in consultant visits and exercise testing and the existence of a large pool of candidates who do not have HAC. Those in favour of more leniency recognise the character-building effect of overcoming the disability of asthma, the high level of motivation and even of athletic achievement in some asthmatics, the uncertainty of prognosis in any given individual and the possibility that a stricter policy may lead to a higher prevalence of concealment.

The published literature on the natural history of asthma, whilst not directed primarily to the question of military recruitment, can be used to develop an estimate of the likely prognosis of 16-18 year olds who are in remission following childhood asthma. The various studies define asthma in different ways, stratify patients into different groups, recruit subjects at different ages and from different sources (hospital, general practice, schools) and follow up for different lengths of time. It is therefore not feasible to work out an average prognosis from all the published literature. All agree that severe asthma in childhood is strongly correlated with a worse prognosis in adult life and that milder childhood asthmatics have a greater chance of being wheeze-free in adult life.
A series of studies from Melbourne, Australia ${ }^{4,11-14}$ has followed groups of children identified throughschools at age 7 years up to the age of 28 years. For our present purposes, we are interested in their milder groups of asthmatics at the ages of $14,18,21$ and 280 years. Those who fall into their two most severe groups at 21 and 28 years can be classified together as 'worse: asthmatics' and it seems reasonable to deduce that theyos would be unsuitable for military service. 'Mildo asthmatics'had not suffered wheeze in the three monthso before the specified birthday and those described as 'wheeze free' had been so for three years. Table 5 gives the outcome of the milder childhood asthmatics at ageso 18,21 , and 28 years and is obtained by combining figures from different groups in the original papers. An $\vec{O}$ important additional factor is that, although the $\overrightarrow{-}$ percentages in the three categories were similar at age $\vec{\sigma}$ 21 years and age 28 years, considerable cross-over of individuals occurred during that period, so that about $30 \%$ moved to worse groups, and about $30 \%$ to less? severe groups $^{14}$. This means that, had the subjects beenc $\vec{\omega}$ servicemen, a larger percentage would have risked downgrading or discharge at some time during their third decade.

Table 6 concentrates on the status at 28 years efo

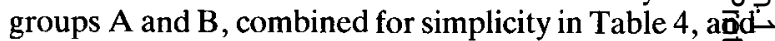
includes also those classified as group $\mathrm{C}$. These wefe more severe asthmatics at age 14; they had wheezed the year before their 14th birthday, but less frequenfly than once per week. They are included here to showoo their worse prognosis and also because some childhoogd asthmatics of this severity could have remitted at age 440 and been recruited into the Army at age 16-18.

Also included in Table 6 , are equivalent figureso derived from Blair's study ${ }^{15,16}$ of children identified ino general practice in London and followed for 20 years. $\stackrel{\odot}{\mathcal{D}}$ At the start of the study these had less than 3 attacks per $\Rightarrow$ year, attacks were clear in 1-3 days, required only 3 bronchodilator therapy and did not cause absence from? school. Again the two most severe groups, defined byọ. Blair as 'recurrent' and 'chronic' have been combined as 'severe'. Allowing for different definitions, it will be seen that the results are of the same order as found in?

Table 5

Melbourne Studies

Status at 14 years: 5 episodes of wheeze or less (A)

or

More than 5 episodes, but wheeze free for 1 year $+(B)$

\begin{tabular}{|c|c|c|c|}
\hline Status at Age: & Wheeze Free \% & Mild Asthma \% & Worse Asthma \% \\
\hline 18 years $^{11}$ & 83 & 17 & $<1$ \\
\hline 21 years $^{12}$ & 55 & 22 & 23 \\
\hline 28 years $^{14}$ & 54 & 19 & 27 \\
\hline
\end{tabular}


Table 6

Tabulation of Outcome Results

\begin{tabular}{|c|c|c|c|}
\hline \multirow[b]{2}{*}{ Status in childhood } & \multicolumn{3}{|c|}{ Status at 28 yrs or in 3rd Decade } \\
\hline & $\begin{array}{c}\text { Wheeze } \\
\text { Free } \\
\% \\
\end{array}$ & $\begin{array}{c}\text { Mild } \\
\text { Asthma } \\
\%\end{array}$ & $\begin{array}{c}\text { Severe } \\
\text { Asthma } \\
\%\end{array}$ \\
\hline \multicolumn{4}{|l|}{ MELBOURNE Group ${ }^{14}$} \\
\hline$A<5$ episodes & 52 & 24 & 24 \\
\hline B $>5$ episodes but free 1 year + & 55 & 15 & 30 \\
\hline$C$ Wheeze in last year but $<1$ per week & 16 & 22 & 62 \\
\hline$A+B$ & 54 & 19 & 27 \\
\hline$A+B+C$ & 39 & 20 & 41 \\
\hline \multicolumn{4}{|l|}{ BLAIR $^{15}$} \\
\hline $\begin{array}{l}\text { "Mild" asthma in childhood } \\
\text { (See text for definition) }\end{array}$ & 36 & 35 & 29 \\
\hline
\end{tabular}

Melbourne groups A, B and C. The results of studies elsewhere can also be seen as broadly compatible ${ }^{17-20}$.

To apply these results to the military situation, it is necessary to make allowance for the intensity of exercise required by Service life and the well known fact that civilians, by contrast, may not exercise sufficiently to know that they could suffer from exercise-induced asthma. The cross-over effect would also make the service dropout rate higher than civilian prognosis figures indicate, but on the other hand recruit selection procedures should help to exclude the more severe asthmatics and those who are currently asthmatics.

\section{Conclusions}

Taking these factors into account a reasonable prediction would be as follows. If 100 recruits with a history of childhood asthma were accepted into the Army under the present policy and followed up to their late twenties, assuming that none left the service for other reasons, 40 would be wheeze free, 25 would have experienced sufficient wheeze to risk downgrading and even medical discharge and 35 would have been discharged because of serious asthma. The majority of these discharges would have been in those under the age of 22 years and some 15-20 would have been during basic training.

Various opinions could be held as to whether this level of dropout is acceptable. Possible future attempts to reduce it might be preceded by a prospective study to determine the accuracy of the prediction, but a relatively long term study would be required and this would need a degree of continuity unusual in the Service. The policy could be changed on the basis of present evidence to exclude all candidates with a childhood asthma history. This would greatly reduce the cost and manpower involved in consultant referral and exercise testing.
The results of the retrospective study presented here, however, suggest that a reasonable compromise solution would be to reject teenage candidates with $\mathrm{HAC}$ but encourage them to apply again after their 22nd birthdayo if they had been free of wheeze for four years. They@ could then be accepted provided exercise testing showed $\mathbb{Q}_{\mathscr{Q}}$ normal lability. If associated with the rate ofo identification of HAC shown in this study $(43 \%)$, this would avoid a minimum of about 9 discharges per year However a higher rate of detection might be expected under the policy introduced in April 1986 and carefulo history taking associated with strict enforcement might reduce discharge due to asthma by as much as $40 \%$ to 30 discharges per year.

\section{Acknowledgements}

The author is grateful to Mrs Margaret Sims of MOD Medical Statistics, Stanmore, for advice and for the provision of the data on which much of this study is based and to physician colleagues for their encouragement and helpful comments.

\section{REFERENCES}

1. Gross $\mathrm{N}$ J. What is this thing called love? - or, defining asthma, Am Rev Respir Dis 1980; 121 : 203-4.

2. SCADDING J G. Asthma and bronchial reactivity. $\mathrm{Br}$ Med $J$ 1987; 294: 1115-6.

3. McNiCHOL $\mathrm{KN}$ and WiLLIams H B. Spectrum of asthma in children. Br Med J 1973; (4): 7-18.

4. Williams $\mathrm{H}$ and McNichol $\mathrm{K}$ N. Prevalence, natural history and relationship of wheezy bronchitis and asthma in children. Br Med J 1969; (4): 321-5.

5. CARson $J$ and Winfield $C R$. Exercise testing in Servicemen with asthma and its application to the assessment of potential recruits. J R Army Med Corps 1983; 129: 14-18. 
6. LYNCH-BLOSSE R H. A study into medical wastage of recruits. J $R$ Army Med Corps 1987; 133: 43-49.

7. WINFIELD C R and CARSON J. Exercise induced asthma in young male asthmatics with symptoms and in remission. $J$ R Army Med Corps 1985; 131: 21-23.

8. Hetzel M R and Clark T J H. Adult asthma. In: Clark T J H and Godfrey S, eds. Asthma. London: Chapman and Hall, 2nd edition 1983: 457-489.

9. Bonner J R. The epidemiology and natural history of asthma. Clin Chest Med 1985; 5(4):557-65.

10. Martin A J Landau L I and Phelan PD. Natural history of allergy in asthmatic children followed to adult life. Med J. Aust 1981; 2 (9): 470-4.

11. Williams H E and Phelan P D. The natural history of childhood asthma through adolescence. Aust Paediatr $J$ 1977; 13: 88-90.

12. MARTin A J et al. The natural history of childhood asthma to adult life. $\mathrm{Br}$ Med $J 1980 ; 280: 1397-1400$.

13. Martin A J et al. Asthma from childhood at age 21 : the patient and his disease. $B r$ Med J 1982; 284: 380-2.
14. Kelly W J W et al. Childhood asthma in adult life: a further study at 28 years of age. $B r$ Med $J$ 1987; 294:105962.

15. BLAIR H. Natural history of childhood asthma. Arch Dis $\stackrel{\triangleright}{\varrho}$ Child 1977; 52: 613-19.

16. BLAIR H. Natural history of wheezing in childhood. $J R$ 응 Soc Med 1979; 72: 42-48.

17. RACKEMANN F M and EDWARDS MC. Asthma in children. A follow-up study of 688 patients after an interval of $20 \stackrel{\mathscr{C}}{\rightarrow}$ years. N Engl J Med 1952; 246: 815-23.

18. Buffum W F and Settipane G A. Prognosis of asthma in childhood. Am J Dis Child 1966; 112: 214-7.

19. JOHNSTONE D E. A study on the natural history of $\Phi$ bronchial asthma in children. Am J Dis Child 1968; 115: صి 213-6.

20. Bronniman S and Burrows B. A prospective study of $\vec{\circ}$ the natural history of asthma. Chest 1986; 90: 480-4.

\section{ACADEMIC ACHIEVEMENTS}

\section{FRCS}

MRCP

FFARCS - Part II

MRCPsych

MRCGP
Major S J E Matthews, RAMC

Major C A J P Royle, RAMC

Captain D C Mabin, RAMC

Captain R J Claydon, RAMC

Major G E P Vincenti, RAMC

Captain J A Barratt, RAMC

Captain D C Bellamy, RAMC

Captain J M Dowling, RAMC

Major E Gordon, RAMC

Captain B L James, RAMC

Captain M J M Knight, RAMC

Major A J Mantell, RAMC

Major R F North, RAMC

Captain R Pounder, RAMC

Captain J H Redman, RAMC

Captain P E Sharples, RAMC

Captain R G Simpson, RAMC

Major J Thomas, RAMC

Captain M A Thorpe, RAMC

Major J M Wells, RAMC

DIH

AFOM
Major P J E Chinneck, RAMC

Major P J E Chinneck, RAMC 